\title{
Intraspecific Competition among Plant Clones
}

\author{
Taizo UCHIDA ${ }^{*}$, Teruo ARASE ${ }^{* *}$, Yang HAI-JUN ${ }^{* * *}$, Zhao YA-NAN ${ }^{* * *}$, Toshimi \\ MUNEOKA ${ }^{*}$ and Natsuko SAKAMOTO* \\ "Obihiro University of Agriculture and Veterinary Medicine, Obihiro, 080-8555 Japan \\ "* Faculty of Agriculture, Shinshu University, Minamiminowa, 399-4598 Japan \\ *** School of Life Sciences, Northeast Normal University, Changchun, 130024 China
}

\begin{abstract}
The present study was conducted to provide information on intraspecific competition using clones of Phragmites australis (Cav.) Trin. ex Steudel (Common Reed). For our purpose, $P$. australis growths under single plantings with identical clones only (intragenotypic experiments) were compared with those under mixed plantings with different clones (intergenotypic experiments) in laboratory conditions. As the results show, there were not significant differences between growths of above-ground organs of $P$. australis clones in intragenotypic experiments and those in intergenotypic experiments. Negative effects, however, were shown in growths of below-ground organs of $P$. australis clones; the dry weights of below-ground organs of $P$. australis clone in intragenotypic experiments were significantly inhibited as compared with those in intergenotypic experiments (89.0\% of the latter). The above-mentioned results suggest $P$. australis has intraspecific competition among identical clones in the root communication. Furthermore, these results would offer meaningful information for revegetation, bio-environmental control and elucidation of succession, or biotechnology which enormously produces the plant clones.
\end{abstract}

Key words: Clone, Intraspecific competition, Phragmites australis (Cav.) Trin. ex Steudel

\section{Introduction}

Plant growth, dominance and distribution are dependent upon interspecific competition for limited resources, light, water and nutrients, and/or their allelopathic potential. Meanwhile, Ambrosia dumosa Payne (Asteraceae) which is one of the desert shrubs and Miscanthus sinensis Anderss. (Eulalia) which is one of the perennial grasses have self-nonself recognition capability, and elongation of these plant roots decrease only after contact with roots of identical species which grow nearby (Mahall and Callaway 1991, 1992, 1996; Nishiwaki and Sugawara 1996). These results suggest plant growth, dominance and distribution are also decided by intraspecific competition besides interspecific competition and/or allelopathic potential.

Explanations for intraspecific competition of other plants have been also sought for many years through descriptive pattern analysis (Yeaton and Cody 1976; Yeaton et al. 1977; Phillips and MacMahon 1981; Cody 1986; McAuliffe 1988) and through experimental field studies (Fonteyn and Mahall 1978, 1981; Robberecht et al. 1983; Ehleringer 1984; Manning and Barbour 1988). These studies have revealed important questions regarding the intraspecific competition, but their resolutions have often not been fine enough to accurately support intraspecific competition in nature. Further works regarding the intraspecific competition are important to describe mechanisms which decide plant growth, dominance and distribution, and they would also be beneficial to revegetation, bioenvironmental control and so on.

The objective of this study is to provide information on intraspecific competition, using clones of Phragmites australis (Cav.) Trin. ex Steudel (Common Reed) which is one of the cosmopolitan Poaceae, perennial large hydrophytes. For our purpose, $P$. australis growths under single plantings with identical clones only (intragenotypic experiments) were compared with those under mixed plantings with different clones (intergenotypic experiments) in laboratory conditions.

\section{Materials and Methods}

\subsection{Plant material}

In the middle of July, $P$. australis culms of identical rhizome origin were, respectively, collected from three different sites, the basins of the Tokachi River, the Kushiro R. and the Shibetsu R. in Hokkaido, northern Japan. These sites are, respectively, $100-190 \mathrm{~km}$ apart, geographically (Fig. 1 and Table 1). The culms were then cut into several segments, $25 \mathrm{~cm}$ lengths with two nodes, for bioassay use.

An invisible small lateral bud is attached to each node of $P$. australis culm (Fig. 2), and the bud can grow as a clone of genetically identical individuals from the culm under moist conditions (Uchida et al. 2003).

2.2 Bioassay of culm segment

Five culm segments from the same site (test culms) 
Table 1. Characteristics of $P$. australis communities from which culms were collected in this study.

\begin{tabular}{lrrrrrrr}
\hline \multirow{2}{*}{\multicolumn{1}{c}{ Items }} & \multicolumn{7}{c}{ Sampling sites } \\
\cline { 2 - 7 } \multicolumn{1}{c}{ Tokachi R. } & \multicolumn{1}{c}{ Kushiro R. } & Shibetsu R. & $p$-value \\
\hline Culm length $(\mathrm{cm})$ & $175.6 \pm 6.3$ & $\mathrm{~A}$ & $176.6 \pm 4.2$ & $\mathrm{~A}$ & $171.0 \pm 15.5$ & $\mathrm{~A}$ & $p=0.254$ \\
Number of leaves (No. / culm) & $14.0 \pm 0.7$ & $\mathrm{~A}$ & $13.6 \pm 0.9$ & $\mathrm{~A}$ & $13.4 \pm 0.9$ & $\mathrm{~A}$ & $p=0.531$ \\
Number of culms (No. / m ${ }^{2}$ ) & $126.7 \pm 28.1$ & $\mathrm{~A}$ & $146.7 \pm 19.7$ & $\mathrm{~A}$ & $138.7 \pm 18.0$ & $\mathrm{~A}$ & $p=0.575$ \\
Basal diameter of culm (mm) & $8.0 \pm 0.7$ & $\mathrm{~A}$ & $8.0 \pm 0.7$ & $\mathrm{~A}$ & $7.5 \pm 0.9$ & $\mathrm{~A}$ & $p=0.570$ \\
\hline
\end{tabular}

Mean \pm S.D. The levels of significance are also shown. Within any row, values followed by the same letter are not significantly different using a one-way anlysis of variance.

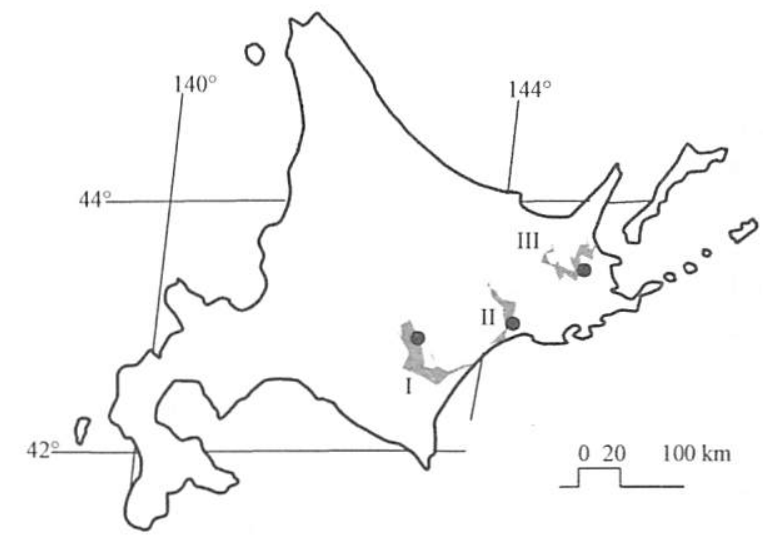

Fig. 1. Locations of sampling sites in this study, in Hokkaido, northern Japan.

I, II and III indicate the basins of the Tokachi River, the Kushiro R. and the Shibetsu R., respectively. $\bullet$ : Sampling site.

were placed in a plastic chamber with those from the other site (target culms) for intergenotypic experiments (Fig. 3). For intragenotypic experiments, five culm segments from the same site (test culms) were placed in a plastic chamber with five target culms from the same site. Distilled water was added to the plastic chamber, and the total volume of distilled water was maintained at 400-500 milliliters during the experimental period. Five replications were used for each experiment or all the site combinations. The prepared plastic chambers were then incubated at $25^{\circ} \mathrm{C}$ with 12 $\mathrm{h}$ of light for ninety days.

The number of lateral buds elongated from test culms and their heights were measured periodically. The former was expressed as a percentage, elongation rate of lateral bud (\%), using the following formula (1). Furthermore, dry weights of above- and below-ground organs of lateral buds elongated from the test culms were measured after ninety days of incubation. Aboveground organs are stems, laminae and sheaths, and below-ground organs consist of adventitious roots and rhizomes.

$$
\begin{aligned}
& \text { Elongation rate of lateral bud }(\%) \\
& \qquad=N L B / T N N \times 100
\end{aligned}
$$

Where $N L B$ shows the number of lateral buds elongated from test culms per plastic chamber, and $T N N$ is ten, the total number of nodes (lateral buds) of test culms per plastic chamber (Fig. 3).

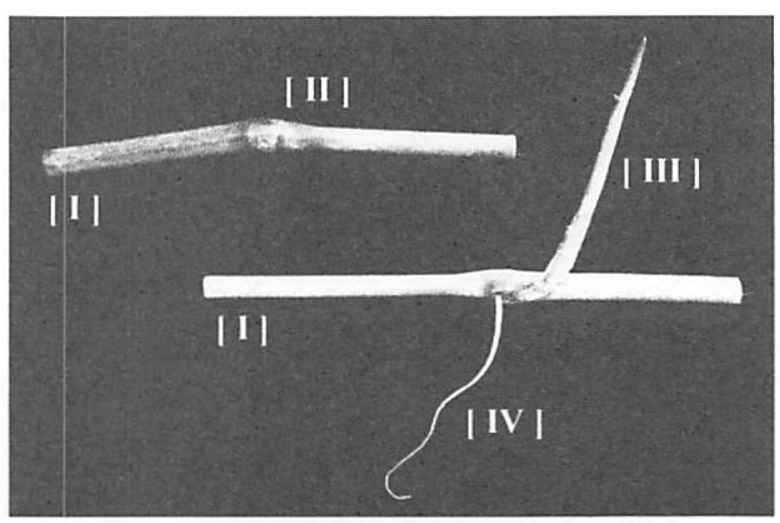

Fig. 2. Lateral bud which grows as a clone.

[ I ]: Segment of P. australis culm. [ II ]: Node and an invisible small lateral bud. [ III ]: Lateral bud elongated from the culm. [ IV ]: Adventitious root.
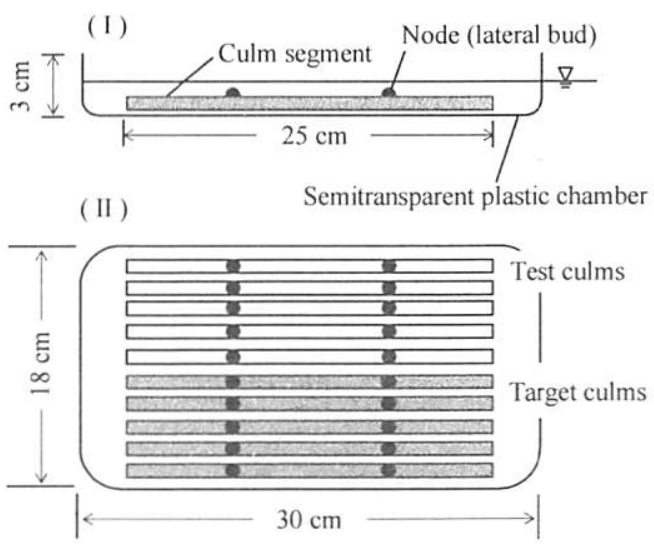

Fig. 3. Schematic drawings of experimental chamber.

( I ) and ( II ) indicate side and face views of the chamber, respectively.

\subsection{Data analysis}

A one-way analysis of variance or t-test was performed on the data. Probabilities less than 0.05 were considered significant.

\section{Results and Discussion}

\subsection{Lateral bud elongations}

When test culms were placed with target culms from 
the same site (intragenotypic experiments), lateral buds elongation from test culms were observed on and after eight days of incubation (Fig. 4-(1)). The elongation rate of lateral buds increased rapidly from $14.6 \%$ at eight days of incubation to $84.1 \%$ at twelve days of incubation, and the rate had no change afterwards. Similarly, lateral buds elongation from test culms placed with target culms from the other site (intergenotypic experiments) were also observed on and after eight days of incubation. The elongation rate of lateral buds increased rapidly to $82.3 \%$ at sixteen days of incubation, and no change was shown in the rate afterwards. Within each experiment, there were not significant differences between final means at ninety days of incubation in elongation rate of lateral buds $(p=0.890)$.

\subsection{Lateral bud heights}

When test culms were placed with target culms from the same site (intragenotypic experiments), heights of lateral buds elongated from test culms increased gradually to $22.9 \mathrm{~cm}$ at ninety days of incubation (Fig. 4-(2)). Heights of lateral buds elongated from test culms placed with target culms from the other site (intergenotypic experiments) also indicated the same tendency as change of heights in intragenotypic experiments, and they reached $20.8 \mathrm{~cm}$ at ninety days of incubation. Within each experiment, significant differences between final means at ninety days of incubation were not shown in lateral bud heights $(p=0.275)$.

\subsection{Lateral bud weights}

When test culms were placed with target culms from the same site (intragenotypic experiments), dry weights of above-ground organs of lateral buds elongated from test culms were $4.64 \mathrm{~g}$ per chamber at ninety days of incubation (Fig. 5-(1)). Meanwhile, dry weights of above-ground organs of lateral buds elongated from test culms were $4.82 \mathrm{~g}$ per chamber at ninety days of incubation when placed with target culms from the other site (intergenotypic experiments). There were insignificant differences between dry weights of above-ground organs of lateral buds elongated from test culms in intragenotypic experiments and those in intergenotypic experiments $(p=0.662)$.

Significant differences, however, were shown $(p<0.001)$ between dry weights of below-ground
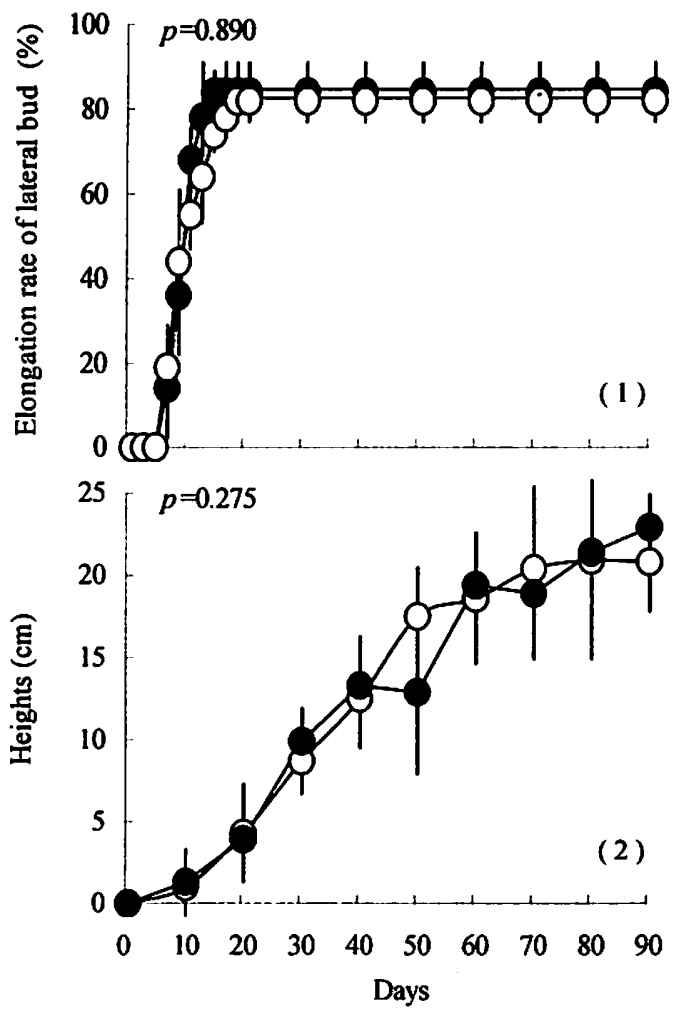

Fig. 4. Changes of elongation rate of lateral bud (1) and lateral bud heights (2).

:Intragenotypic experiments $(n=15) .0$ : Intergenotypic experiments $(n=30)$. Vertical bars show standard deviation. Differences between final means in each experiment were determined using t-test, and the levels of significance are also shown.

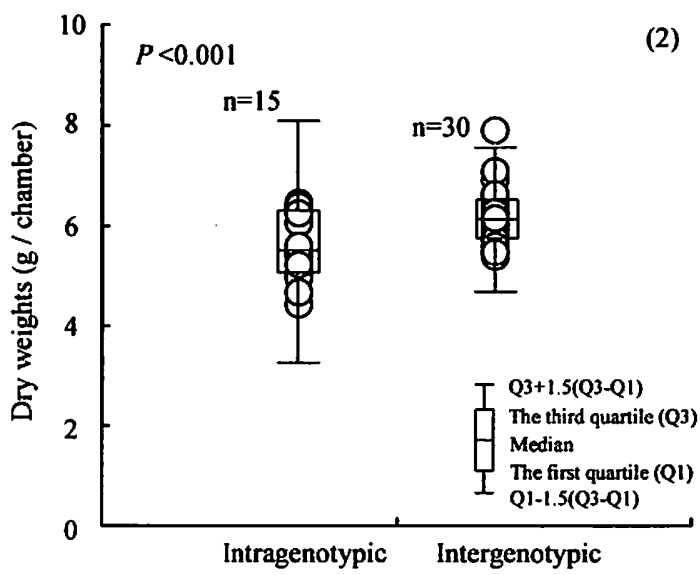

Fig. 5. Comparison between intragenotypic and intergenotypic experiments in dry weights of lateral buds elongated from test culms after ninety days of incubation. (1) and (2) show above- and below-ground organs, respectively. Differences between means in each experiment were determined using t-test, and the levels of significance are also shown. 


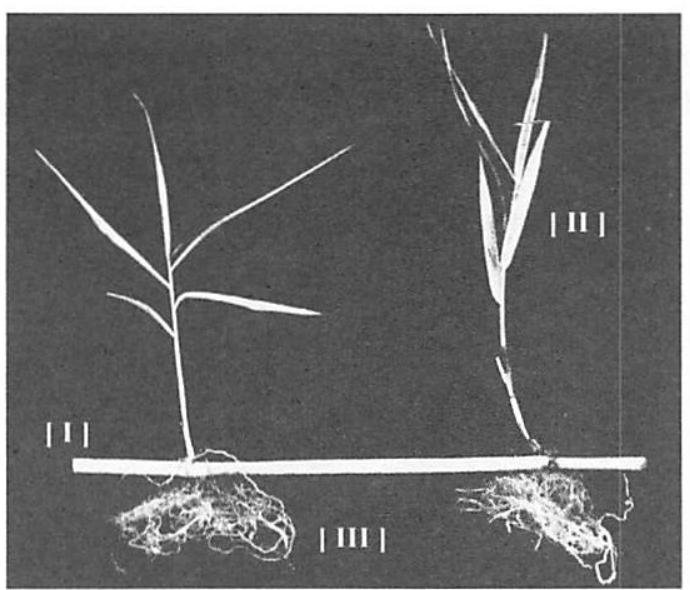

Fig. 6. Lateral buds elongated from test culm in intergenotypic experiments. [ I ]: Culm segment. [ II ]: Aboveground organs of lateral bud. [ III ]: Below-ground organs of lateral bud.

organs of lateral buds elongated from test culms in intragenotypic experiments and those in intergenotypic experiments (Fig. 5-(2)); their dry weights per chamber in intragenotypic and intergenotypic experiments were, respectively, $5.52 \mathrm{~g}$ and $6.18 \mathrm{~g}$, the former was significantly lighter $(89.0 \%$ of the latter $)$. Meanwhile, lateral buds elongated from test culm in intergenotypic experiments are shown in Fig. 6. It is proved that lateral buds grow as clones of genetically identical individuals from culm segments.

It can not be explained whether dry weights inhibition of below-ground organs of lateral buds in intragenotypic experiments was caused by self-nonself recognition capability (Mahall and Callaway 1991, 1992, 1996; Nishiwaki and Sugawara 1996) or allelopathic potential. The findings in this study, however, would suggest growth, dominance and distribution of $P$. australis are dependent upon intraspecific competition among identical clones, especially in subterranean parts. One $P$. australis community consists of some genetically different units (Dykyjová 1978), and such phenomenon would also support existence of intraspecific competition of $P$. australis among identical clones, which was suggested in this study.

The above-mentioned results using $P$. australis clones would provide meaningful information for revegetation, bio-environmental control, elucidation of succession, biotechnology and so on. A very accurate solution on the mechanism of intraspecific competition among plant clones, however, is required for the further development of biotechnology which enormously produces the plant clones.

\section{References}

Cody, M. L., 1986: Spacing patterns in Mojave Desert plant communities: near-neighbor analysis. J. Arid Environ., 11, 199-217.

Dykyjová, D., 1978: Intraspecific and clonal variability and its importance for production estimates. In Pond littoral ecosystems; structure and functioning, Ecological Studies vol. 28 (eds. by Dykyjová, D. and Kvet, J.), Springer-Verlag, Berlin, Heidelberg and New York, pp. 159-161.

Ehleringer, J. R., 1984: Intraspecific competitive effects on water relations, growth and reproduction in Encelia farinosa. Oecologia, 63, 153-158.

Fonteyn, P. J. and Mahall, B. E., 1978: Competition among desert perennials. Nature, 275, 544-545.

Fonteyn, P. J. and Mahall, B. E., 1981: An experimental analysis of structure in a desert plant community. J. Ecol., 69, 883-896.

Mahall, B. E. and Callaway, R. M., 1991: Root communication among desert shrubs. Proc. Natl. Acad. Sci. USA, 88, 874-876.

Mahall, B. E. and Callaway, R. M., 1992: Root communication mechanisms and intracommunity distributions of two Mojave Desert shrubs. Ecology, 73, 2145-2151.

Mahall, B. E. and Callaway, R. M., 1996: Effects of regional origin and genotype on intraspecific root communication in the desert shrub Ambrosia dumosa (Asteraceae). Am. J. Bot., 83, 93-98.

Manning, S. J. and Barbour, M. G., 1988: Root systems, spatial patterns, and competition for soil moisture between two desert subshrubs. Am. J. Bot., 75, 885-893

McAuliffe, J. R., 1988: Markovian dynamics of simple and complex desert plant communities. American Naturalist, 131, 459-490.

Nishiwaki, A. and Sugawara, K., 1996: Effects of contact with different clone root on root elongation of Miscanthus sinensis. Grassl. Sci., 42(ext.), 54-55 (In Japanese).

Phillips, D. L. and MacMahon, J. A., 1981: Competition and spacing patterns in desert shrubs. $J$. Ecol., 69, 97-115.

Robberecht, R., Mahall, B. E. and Nobel, P. S., 1983: Experimental removal of intraspecific competitions: effects on water relations and productivity of a desert bunchgrass, Hilaria rigida. Oecologia, 60, 21-24.

Uchida, T., Kuroki, T., Nekomoto, K. and Sato Y., 2003: A new method for waterfront revegetation using Phragmites australis (Cav.) Trin. ex Steudel. In XXX CIOSTA-CIGR V Congress Proc. Vol. 1 (ed. by Piccarolo, P.). Università degli Studi di Torino, Trin, pp. 139-146.

Yeaton, R. I. and Cody M. L., 1976: Competition and spacing in plant communities: the northern Mojave Desert. J. Ecol., 64, 689-696.

Yeaton, R. I., Travis, J. and Gilinsky, E., 1977: Competition and spacing in plant communities: the Arizona upland association. J. Ecol., 65, 587-595. 